\title{
Isolated Tuberculosis of Rib: A Case Report
}

\section{Santosh T}

Pathology and Lab Medicine, PDCC Dermatopathology, AlIMS, Saket Nagar, Bhopal, MP, India

"Corresponding author: Santosh T, Pathology and Lab Medicine, PDCC Dermatopathology, AlIMS, Saket Nagar, Bhopal, MP, India, Tel: 9584873660; E-mail: born_vss@yahoo.co.in

Received date: January 3, 2019; Accepted date: February 25, 2019; Published date: February 28, 2019

Copyright: () 2019 Santosh T. This is an open-access article distributed under the terms of the Creative Commons Attribution License, which permits unrestricted use, distribution, and reproduction in any medium, provided the original author and source are credited.

\begin{abstract}
Background: Rib tuberculosis is an uncommon form of osteoarticular type of tuberculosis accounting for $<5 \%$ of cases of bone and joint infection.

Case presentation: We report a case of young adult with rib destruction. Tuberculosis was confirmed on cytology with CB-NAAT testing. There were no lesions in lung parenchyma or any lymphadenopathy. The patient responded completely to the anti-tuberculosis therapy without any surgical intervention.

Conclusion: Isolated tuberculosis of rib is very rare and should be included in the differentials of clinical examination. FNAC with ROSE can be a useful technique for early diagnosis and start of anti-tubercular drugs which forms the main stay of treatment with good recovery.
\end{abstract}

Keywords: Tuberculosis; Ribs; Cytology; Rapid on-site evaluation ZN stain; CB-NAAT

Abbreviations ADA: Adenosine Deaminase; CB-NAAT: Cartridge Based Nucleic Acid Amplification Test; FNAC: Fine Needle Aspiration Cytology; HCV Hepatitis C Virus; HIV: Human Immunodeficiency Virus; MTB: Mycobacterium tuberculosis, PAP: Papanicolaou; TB: Tuberculosis.

\section{Introduction}

In developing countries like India, tuberculosis (TB) is a significant public health problem. The reason behind this is widespread immigration, malnutrition and low immune status [1]. Musculoskeletal tuberculosis accounts for $15 \%$ of all extra pulmonary localizations [2]. Rib tuberculosis is an uncommon form of osteoarticular type of tuberculosis accounting for $<5 \%$ of cases of bone and joint infection [3]. The patients can present as isolated lesion without any primary foci in the lung parenchyma or other ribs. We hereby present a case of isolated tuberculosis over posterior 9th rib as the initial presentation without any lesion in the lungs.

\section{Case Report}

A 22-year male patient presented to medicine clinic with complaints of tenderness over right back for 6 months. General examination revealed a swelling over right infrascapular region. As Figure 1a shows, he had no lymphadenopathy or hepatosplenomegaly. There was no history of any TB contact of the patient. Chest-X-ray revealed a lytic lesion in posterior part of 9th rib, rest of lung parenchyma was normal. His complete blood picture revealed: haemoglobin: $11.2 \mathrm{mg} / \mathrm{dl}$, total leucocyte count: $7,200 / \mathrm{mm}^{3}$, differential count revealed mild eosinophilia; Erythrocyte sedimentation rate (ESR): $52 \mathrm{~mm} / 1 \mathrm{st} \mathrm{hr}$. Zeil Neelson (ZN) stain for acid fast bacilli was done from the sputum sample for three consecutive days and was negative. Cartridge based nucleic acid amplification technique (CB-NAAT) was done using the
Gene expert machine was also done from the sputum sample and was negative. His serum ADA levels were elevated (42.3 U/L) (Figure 1b). Mantoux testing was done on right forearm revealed a $13 \times 12 \mathrm{~mm}$ induration after $48 \mathrm{~h}$. His viral markers (Human immunodeficiency virus, Hepatitis B, Hepatitis C) were non-reactive. With a clinical suspicion of cold abscess/fungal lesion, the patient was sent for FNAC from local site (rib).

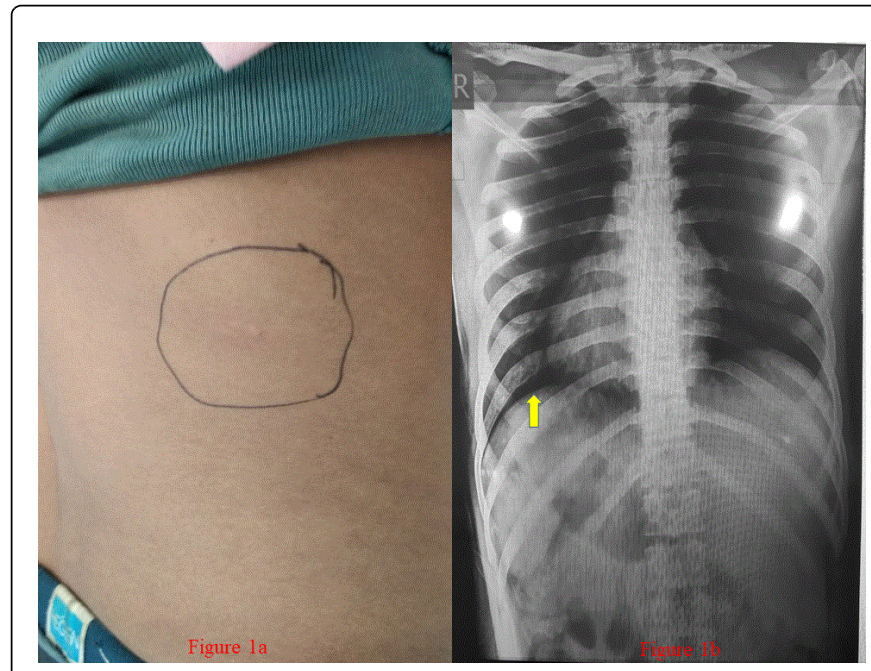

Figure 1: (a) Patient with subcutaneous swellings over right infrascapular region measuring approximately $2 \times 1.5 \mathrm{~cm}$; (b) Chest $\mathrm{X}$ ray showing a lytic lesion in 9 th rib shaft region. 
Page 2 of 3

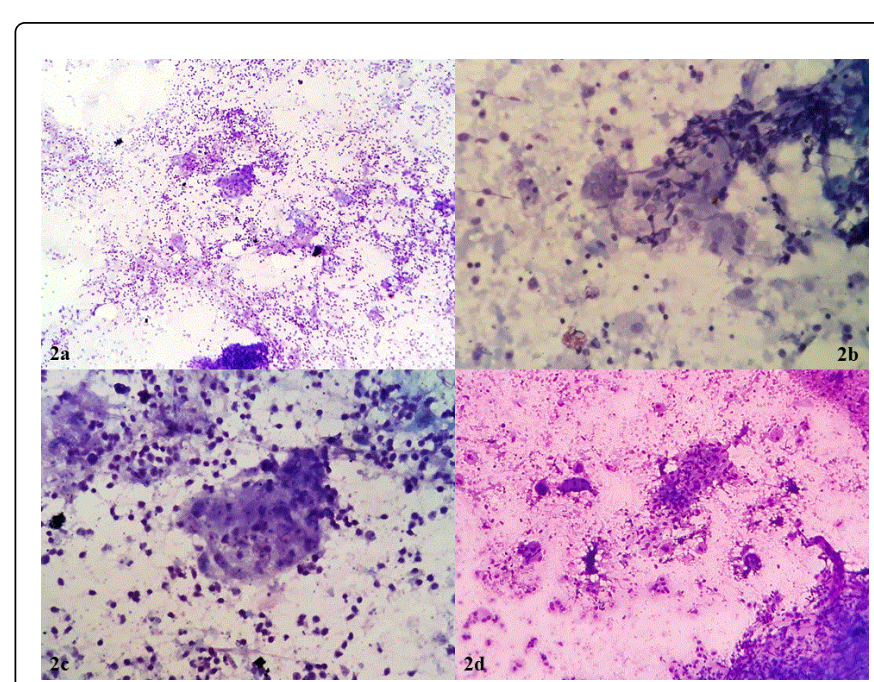

Figure 2: Cytosmears showing granular necrotic material in background along with few lymphocytes, macrophages, langhan's giant cell, epithelioid granulomas and occasional osteoclasts (Toluidine Blue, x10, x40; Geimsa, x10).

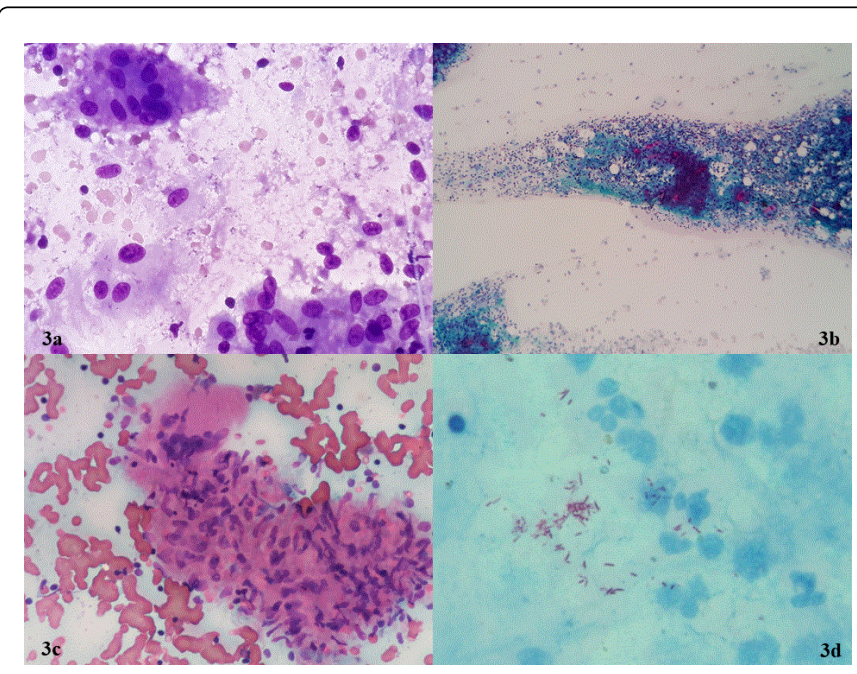

Figure 3: Cytosmears showing granular necrotic material in background along with few lymphocytes, macrophages, langhan's giant cell, epithelioid granulomas and occasional osteoclasts. AFB stain showing tubercular bacilli. (Geimsa, x40; PAP, x10, x40; ZN Stain, $x 100)$.

On examination, a swelling in right infra scapular region over the 9th rib region measuring $3 \times 2.5 \mathrm{~cm}$, well defined, soft, tender. Fine needle aspiration was done using 23 gz needle. Aspirate was pus like material. Rapid onsite evaluation using toluidine blue stain followed by Geimsa and PAP staining was done. Smears showed predominantly granular necrotic material in background along with few lymphocytes, macrophages, epithelioid granulomas, langhan's giant cell and occasional osteoclasts (Figures $2 \mathrm{a}-\mathrm{d}$ and $3 \mathrm{a}-\mathrm{c}$ ), with the diagnosis of necrotising granulomatous lesion. $\mathrm{ZN}$ staining from the aspirate was positive for Mycobacteria (Figure 3d). We also did CB-NAAT from the aspirated sample of rib FNA which was reported as Mycobacterium tuberculosis (low detected) with rifampicin sensitivity. Later the sample was sent for culture confirmation and was reported positive after 3 weeks of incubation. Based on the reports from FNA and CBNAAT, he was restarted on anti-tubercular medication and is currently asymptomatic since last 3 months.

\section{Discussion}

Musculoskeletal tuberculosis the commonest form of extra pulmonary tuberculosis is usually a late complication of tuberculosis and thought to occur either due to haematogenous spread or from reactivation of a latent focus of mycobacteria [3,4]. It accounts for $10-15 \%$ of all the tuberculosis cases in developing world. While in western world it accounts for only 1-2\% of cases [5]. Majority of the cases occur in children and young adults and the diagnosis is usually delayed for several weeks [2]. In skeletal system tuberculosis, vertebral column (50\%) is the commonest site followed by hip (15\%) and knees (5\%). Involvement of the rib in skeletal tuberculosis is being reported as $0-5 \%$ of the bone tuberculosis and it is the commonest inflammatory disorder involving the rib [6].

The most frequent site of tuberculous involvement in ribs is the shaft (61\%) so was in our case followed by costovertebral joint (31\%) and costochondral (13\%) region. Multi focal involvement of rib is usually seen in immunocompromised patients [7], with an insidious onset, $<50 \%$ of patients have active pulmonary disease at time of presentation [3]. Destruction of bone in tuberculosis results from pressure necrosis by granulation tissue and by the direct action of invading organisms [3]. Mechanism of rib tuberculosis includes: (i) haematogenous dissemination associated with activation of a dormant tuberculous focus (most common); (ii) direct extension from a lymphadenitis of chest wall, and (iii) direct extension from lungs $[1,8]$.

The presenting symptoms of rib tuberculosis are a painful lesion or non-tender chest wall mass or chest pain. The mass can be cystic or doughy. A draining sinus has been seen in $25 \%$ of cases, but this was usually a late finding [2]. Tuberculous bone lesions can resemble pyogenic and fungal infections or bone tumours. Multifocal bone involvement can also occur. Progressive enlargement of surrounding tissue (cold abscess) and destruction of the ribs is hallmark of the tuberculous osteomyelitis. Superficial abscesses burst open to form ulcer or sinus tract [9].

Diagnosis is based on bacteriological and histological confirmation but microbiological confirmation is difficult as tubercular osteomyelitis is paucibacillary. Chest X-Ray may show osteolytic and destructive lesion. Ultrasonography of thorax - may show evidence of hypo-echoic lesion in the chest wall $[2,3]$. FNAC with rapid on-site evaluation may be done for cell block preparation and cytological confirmation of cases with granulomatous reaction and acid-fast bacilli by microscopy $[10,11]$. Inflammatory marker and leukocyte result are often normal. Intradermal reaction is usually positive, but when negative, it does not rule out the underlying diagnosis [10]. Differential diagnosis includes the metastatic or primary tumour, metabolic bone disorder or trauma, fungal infection [2].

Treatment consists of general measures, local wound care and antitubercular drugs (mainstay of treatment). Two months of isoniazid, rifampicin, pyrazinamide and ethambutol once daily is followed by 10 months of isoniazid and rifampicin once daily. Surgery may be helpful in establishing the diagnosis or treating the recurrent or complicated cases by removing the sequestrum $[1,2,12]$. 


\section{Conclusion}

Isolated tuberculosis of rib is rare and should be included in the differentials of clinical examination. FNAC can be a useful technique for early diagnosis and start of anti-tubercular drugs which forms the main stay of treatment with good recovery rate.

\section{References}

1. Gaude GS, Reyas AK (2008) Tuberculosis of the chest wall without pulmonary involvement. Lung India 25: 135-137.

2. Mouhtadi EA, Tarik S, Redouane EF (2016) Tuberculosis of the Rib in A 20 Month's Old Boy. Malaysian Journal of Paediatrics and Child Health 22: 1-5.

3. Nita RS, Devanand C, Sabri MA, Yugesh A, Prachi A (2017) Tubercular Osteomyelitis of rib: An unusual form of skeletal tuberculosis. International Journal of Medical Science and Clinical Inventions 4: 2781-2783.

4. Lee JY (2015) Diagnosis and Treatment of Extrapulmonary Tuberculosis. Tuberc Respir Dis 78: 47-55.
5. Shah BA, Splain S (2005) Multifocal osteoarticular tuberculosis. Orthopaedics 28: 329-332.

6. Sing SK, Gupta V, Ahmad Z (2009) Tubercular osteomyelitis of rib-case report. Respiratory Medicine CME 2: 128-129.

7. Tatelman M, Droulliard EJP (1953) Tuberculosis of ribs. Am J Roentgenol Radium Ther Nucl Med 70: 923-935.

8. Wiebe ER, Elwood RK (1991) Tuberculosis of the ribs - a report of three cases. Respir Med 85: 251-253.

9. Keny SJ (2014) Tuberculosis of rib with cold abscess. JIACM 15: 137-138.

10. Teklali Y, Fellous Alami Z, El Madhi T, Gourinda H, Miri A (2003) Peripheral osteoarticular tuberculosis in children: 106 case reports. Joint Bone Spine 70: 282-286.

11. Santosh T, Kothari K, Patil R, Jogi AK (2018) Bacille Calmette - Guerin lymphadenitis in infants: A lesser known entity - Report of two cases. J Med Sci 38: 239-243.

12. Pigrau-Serrallach C, Rodríguez-Pardo D (2013) Bone and joint tuberculosis. Eur Spine J 22: 556-566. 